\title{
The Efficacy and Safety of OnabotulinumtoxinA with Different Dosages for the Treatment of Overactive Bladder Syndrome: A Systematic Review and Meta-analysis
}

\author{
Lijun Mu ${ }^{1, \dagger}$, Enxu Xie ${ }^{1, \dagger}$, Xinwei Zhang ${ }^{2}$, Juanhua Tian ${ }^{1}$, Meiyu Wang ${ }^{3}$, Dapeng Wu ${ }^{1, *}$, \\ Yuefeng $\mathrm{Du}^{1, *}$ \\ ${ }^{1}$ Department of Urology, the First Affiliated Hospital of Xi'an Jiaotong University, Xi'an, China \\ ${ }^{2}$ Department of Urology, Xi'an Children's Hospital, Xi'an, China \\ ${ }^{3}$ Department of Imaging, the First Affiliated Hospital of Xi'an Jiaotong University, Xi'an, China
}

Email address:

duyuefeng113@163.com (Yuefeng Du)

${ }^{*}$ Corresponding author

$\dagger$ Lijun Mu and Enxu Xie are co-first authors.

\section{To cite this article:}

Lijun Mu, Enxu Xie, Xinwei Zhang, Juanhua Tian, Meiyu Wang, Dapeng Wu, Yuefeng Du. The Efficacy and Safety of OnabotulinumtoxinA with Different Dosages for the Treatment of Overactive Bladder Syndrome: A Systematic Review and Meta-analysis. American Journal of Life Sciences. Vol. 9, No. 5, 2021, pp. 141-148. doi: 10.11648/j.ajls.20210905.16

Received: October 6, 2021; Accepted: October 30, 2021; Published: November 5, 2021

\begin{abstract}
OnabotulinumtoxinA therapy has become widely used in overactive bladder syndrome (OAB), and many relevant articles have been published, however, there is no consensus regarding the clinical effect of onabotulinumtoxinA with the different dosages. Therefore, we conducted this meta-analysis to assess the efficacy and safety of $100 \mathrm{U}, 200 \mathrm{U}$ and $300 \mathrm{U}$ onabotulinumtoxin $\mathrm{A}$ for the treatment of $(\mathrm{OAB})$. In this project, We performed a comprehensive literature search, which was performed using EMBASE, PubMed, Cochrane database, and Google Scholar for randomized controlled trials (from inception to February 2017). As a result, fourteen studies with 1999 participants were selected. For the efficacy, 200 $\mathrm{U}$ of Onabotulinumtoxin A was significantly superior to $100 \mathrm{U}$, especially in the maximum cystometric capacity (MCC) and maximum detrusor pressure (MDP). Also, its subjective cure rate showed the same tendency. There were no statistical differences between $200 \mathrm{U}$ and $300 \mathrm{U}$ in MCC, MDP and subjective cure rate. For the adverse events, there were no statistical differences among $100 \mathrm{U}, 200 \mathrm{U}$ and $300 \mathrm{U}$ OnabotulinumtoxinA in urinary tract infection (UTI) and urinary retention. Therefore, in our study. Compared to $100 \mathrm{U}$ OnabotulinumtoxinA, $200 \mathrm{U}$ OnabotulinumtoxinA has better efficacy while maintaining safety. Although $200 \mathrm{U}$ OnabotulinumtoxinA is comparable to $300 \mathrm{U}$ OnabotulinumtoxinA in terms of safety and efficacy, $200 \mathrm{U}$ OnabotulinumtoxinA is a cost-effective intervention and may appear to be the optimal dosage for $\mathrm{OAB}$ populations.
\end{abstract}

Keywords: OnabotulinumtoxinA, Overactive Bladder, Dosages

\section{Introduction}

Overactive bladder syndrome $(\mathrm{OAB})$ is a symptom complex including urgency, with or without urge incontinence, but usually with frequency and nocturia [1]. Treatment for $\mathrm{OAB}$ includes nonpharmacologic methods such as lifestyle modification (fluid restriction, avoidance of caffeine), bladder retraining, and pelvic floor muscle (PFM) exercise. And the treatment has mainly relied on anticholinergic medication in an attempt to block the parasympathetic innervation of the bladder [1]. However, long-term anticholinergic treatment is unsatisfactory because of insufficient effectiveness and annoying side effects [1].

OnabotulinumtoxinA was first reported by van Ermengem in 1897 and is considered the most potent and 
useful biological toxin for humans [3]. It is a neurotoxin produced by the bacterium Clostridium botulinum that prevents acetylcholine release at the neuromuscular junction, resulting in flaccid muscle paralysis [4]. Previous studies have reported on the efficacy and safety of onabotulinumtoxinA compared with placebos. The treatment groups were significantly better in the quality of life (QoL) scores and urodynamic parameters than the control groups, and also showed less adverse effects than the control groups $[1,4-16]$. The use of onabotulinumtoxinA to treat overactive bladder (OAB) symptoms is now commonplace and featured in the majority of continence guideline recommendations in patients refractory to conservative treatment and antimuscarinics [5].

OnabotulinumtoxinA therapy has become widely used, and many relevant articles have been published, however, there is no consensus regarding the clinical effect of onabotulinumtoxinA with the different dosages. Recent studies demonstrated significant dose-dependent improvements in urinary symptoms and urodynamic parameters in patients with OAB [6]. Therefore, we performed this systematic review and meta-analysis to evaluate current evidence in support of the optimal dosage of onabotulinumtoxin $\mathrm{A}$ for patients with $\mathrm{OAB}$. It may provide clinicians with the selection of the best dosage in the $\mathrm{OAB}$ therapy.

\section{Methods}

\subsection{Search Strategy}

wE performed a comprehensive literature search using EMBASE, PubMed, Cochrane database, and Google Scholar from inception to February 2017. The search was performed using the MeSH words combined with free words "overactive bladder", "OAB", "Botulinum toxin" and "onabotulinumtoxinA". Each term was associated with multiple synonyms. The research were restricted to humans and English language. Additionally, we manually searched the references and citation lists of all relevant reviews, the conference proceedings and abstracts from ICS, the American Urological Association (AUA), and the European Association of Urology (EAU) [17]. A literature search was performed independently by two review authors. Finally, all available randomized controlled trials (RCTs) were included in this study. Where reported data were incomplete, The authors were contacted.

\subsection{Eligibility and Exclusion Criteria}

The following inclusion criteria were used to select relevant articles for inclusion in our meta-analysis: (1). A randomized controlled design was used. (2). Patients with symptoms of $\mathrm{OAB}$ with or without urge urinary incontinence (UUI), regardless of gender, race, course of disease and the origin of studies. (3). At least 12 weeks of follow-up. the exclusion criteria include: (1). The patients are pregnancy, or age $\leq 18$ years. (2). $100 \mathrm{U}$ vs. $200 \mathrm{U}$ or $200 \mathrm{U}$ vs. $300 \mathrm{U}$ of onabotulinumtoxinA was not contained.

\subsection{Interventions}

Patients were randomly assigned into 3 groups, including $100 \mathrm{U}, 200 \mathrm{U}, 300 \mathrm{U}$ onabotulinumtoxinA separately. The efficiency and safety of onabotulinumtoxinA compared with placebo had been discussed in other studies, so we only focus on the dosage part of these studies.

\subsection{Types of Outcome Measures}

Subjective cure rate: Keywords as "satisfied", "somewhat satisfied", "complete achievement", "significant progress" and "symptom improvement" were deemed to subjective cured. We took the satisfied number or the percentage of the treated people to analyze.

Objective cure rate: Two key urodynamic parameters such as the increase of maximum cystometric capacity (MCC) and the decrease of maximum detrusor pressure (MDP) were used.

Adverse events: We took the most common adverse events: urinary tract infection (UTI) and urinary retention as the representative complications.

\subsection{Quality Assessment of Studies}

The quality of studies was assessed by two authors according to the Cochrane Collaboration Reviewers' Handbook. They were judged by following criteria: random sequence generation, allocation concealment, blinding of participants and personnel, blinding of outcome assessment, incomplete outcome data, selective reporting, and other bias. Differences were resolved by discussion among the authors.

\subsection{Statistical Analysis}

Meta-analysis was performed using Review Manager version 5.2 (The Cochrane Collaboration, Oxford, United Kingdom). Dichotomous data were expressed as relative risk (RR), and continuous outcomes were expressed as weighted mean difference with $95 \%$ confidence intervals (CIs). Meta-analysis was performed using the fixed effect model or the random effect model, The fixed effect model was used for calculations in the absence of evidence of heterogeneity, and the random effect model was used if heterogeneity was obvious. Statistical heterogeneity was assessed by the $\mathrm{I}^{2}$ test with significance set at $\mathrm{P}<0.05$ and $\mathrm{I}^{2}<50 \%$ [3]. We evaluated whether publication bias through visual inspection of funnel plots for asymmetry. in addition, Sensitivity analysis were limited to studies of higher quality so as reconfirming a similar result. A probability of $P<0.05$ was considered to be statistically significant. 

Overactive Bladder Syndrome: A Systematic Review and Meta-analysis

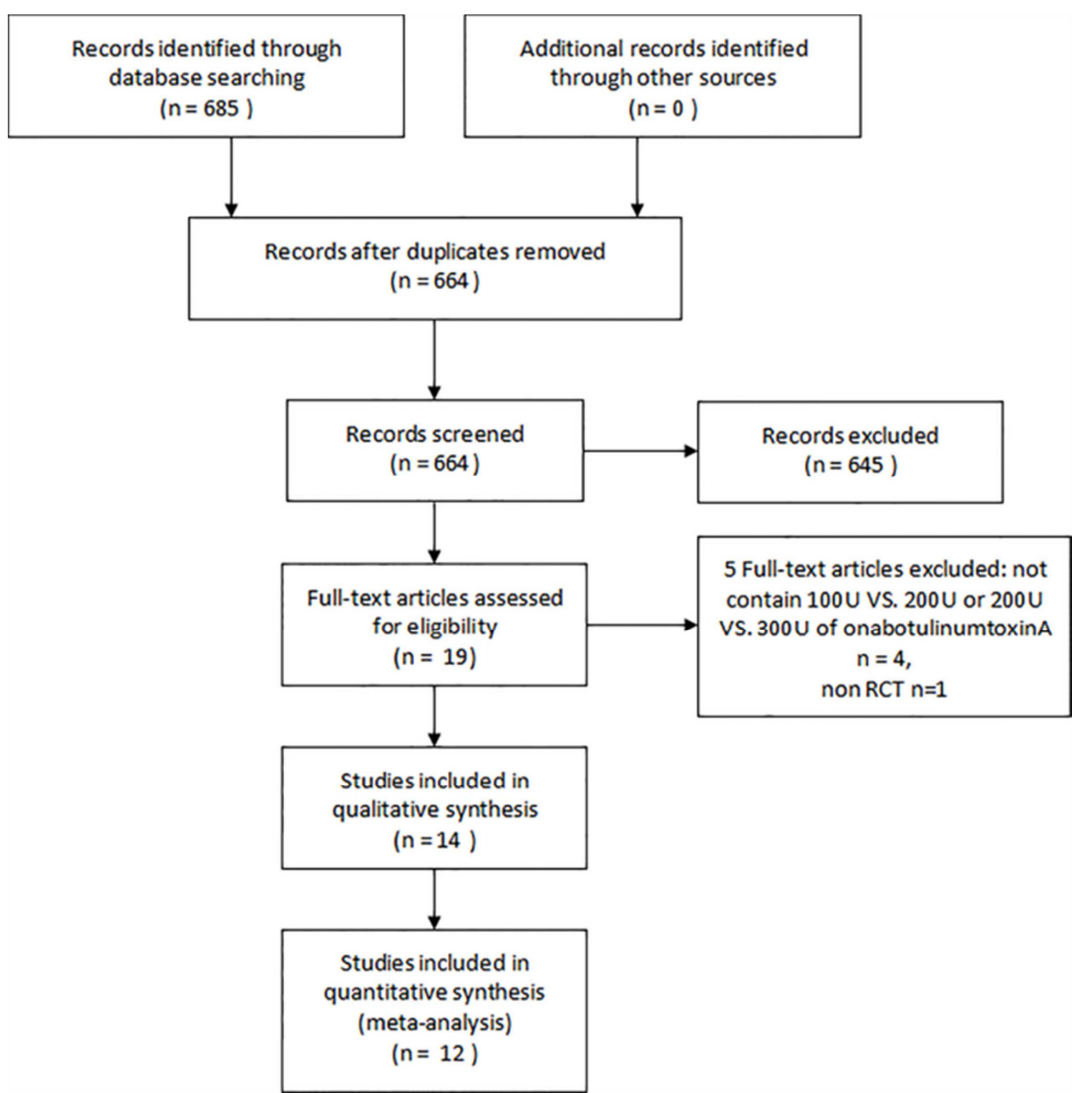

Figure 1. Flow diagram.
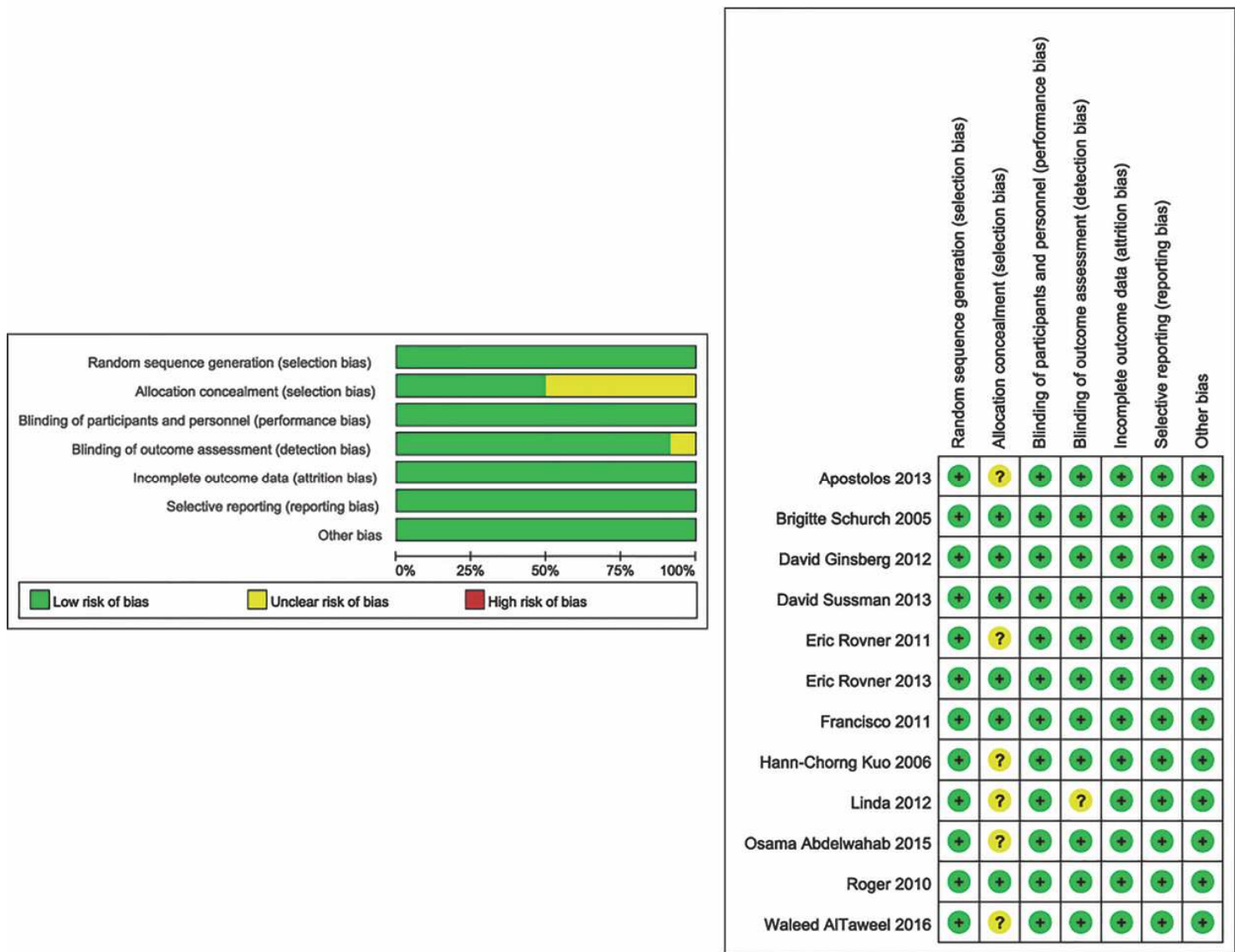

Figure 2. The results for the assessment of bias risk. 


\section{Results}

\subsection{Description of Studies}

Figure 1 presents the process of literature screening. 685 records were identified as being relevant to the present study by the electronic searches of the 3 databases. After excluding 671 records that did not meet eligibility criteria, leaving 14 studies were included in the qualitative synthesis. The reported data were insufficient for 2 of the 14 records, thereby, a total of 12 studies were included for meta-analysis. The results for the assessment of bias risk in the 12 studies included in the quantitative synthesis (meta-analysis) are shown in Figure 2. Overall, every trial was double-blind and had a randomized controlled design. Specifically, 7 trials compared $100 \mathrm{U}$ with $200 \mathrm{U}$, and 9 trials compared $200 \mathrm{U}$ with $300 \mathrm{U}$. The baseline characteristics of the studies included in our meta-analysis are showed in Table 1. Eleven of the 14 studies had received support from Allergan Inc..[1, 4, 6-10, 13-16] Most of the research (78.6\%) were carried out in the US and Europe.

Table 1. The baseline Table characteristics of the studies.

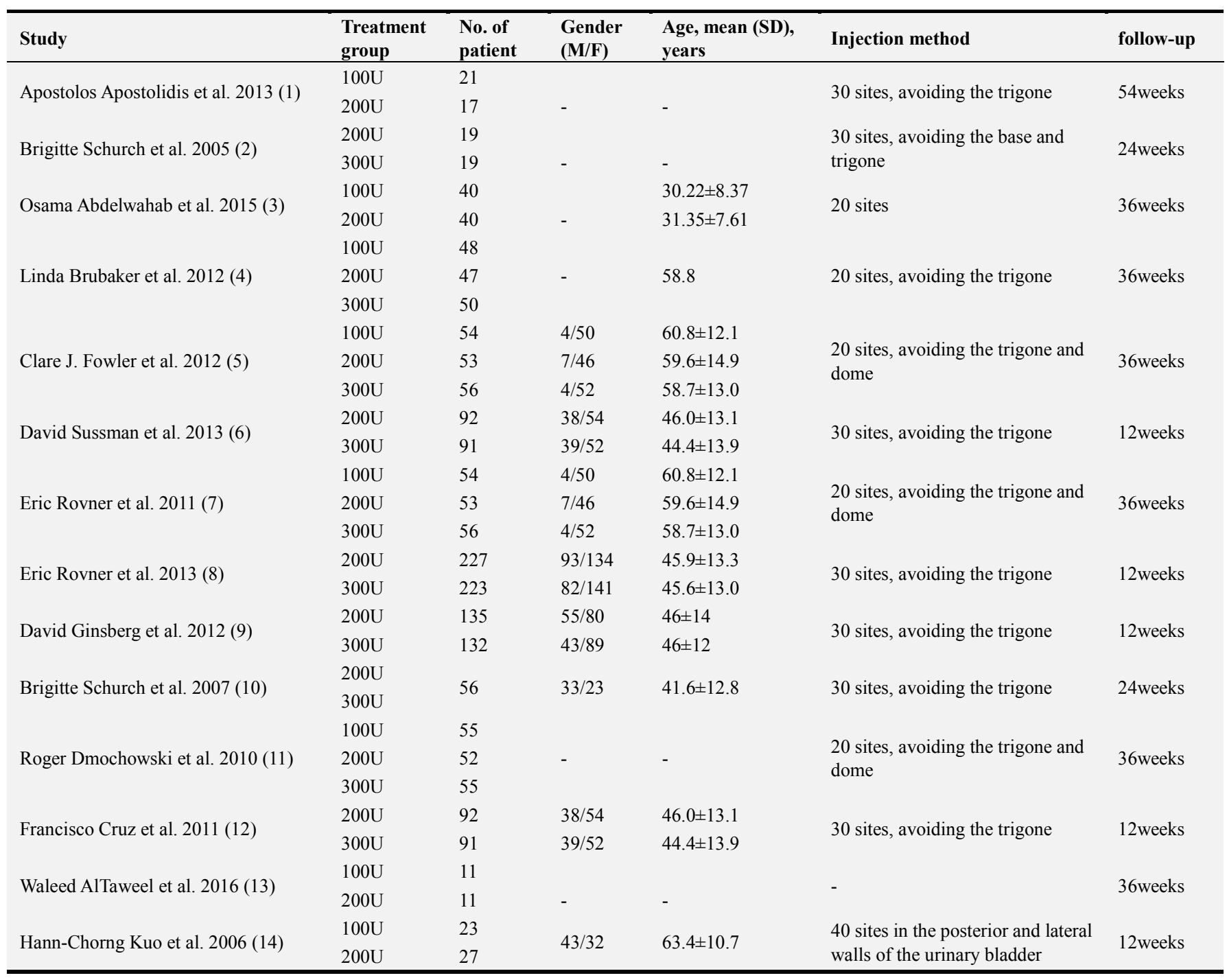

\subsection{Efficacy in Different Dosages}

In order to find out the differences between different dosages of the onabotulinumtoxinA, the analyses were divided into two subgroups: Group onabotulinumtoxinA $100 \mathrm{U}$ vs. $200 \mathrm{U}$, and group onabotulinumtoxinA $200 \mathrm{U}$ vs. $300 \mathrm{U}$. Three studies [6, 9, 16] were evaluated about the subjective cure rate of onabotulinumtoxinA $100 \mathrm{U}$ vs $200 \mathrm{U}$, and four $[6,8,9,11]$ about onabotulinumtoxinA $200 \mathrm{U}$ vs. $300 \mathrm{U}$ with the longest follow-up times respectively. The analysis showed that the subjective cure rate of $200 \mathrm{U}$ was higher than $100 \mathrm{U}(P<0.05$, RR: $0.78,95 \%$ CI: $0.63 \sim 0.96)$. On the contrary, there was no statistical differences between $200 \mathrm{U}$ and $300 \mathrm{U}(P=0.93$, RR: 1.01, 95\%CI: 0.86 1.17) (Figure 3). One study observed the QoL scores of $200 \mathrm{U}$ and $300 \mathrm{U}$, and there were no statistical differences between them [14]. Urodynamic parameters Comparison of urodynamic parameters include MCC and MDP at the longest fellow-up times after treatment to baseline data. 


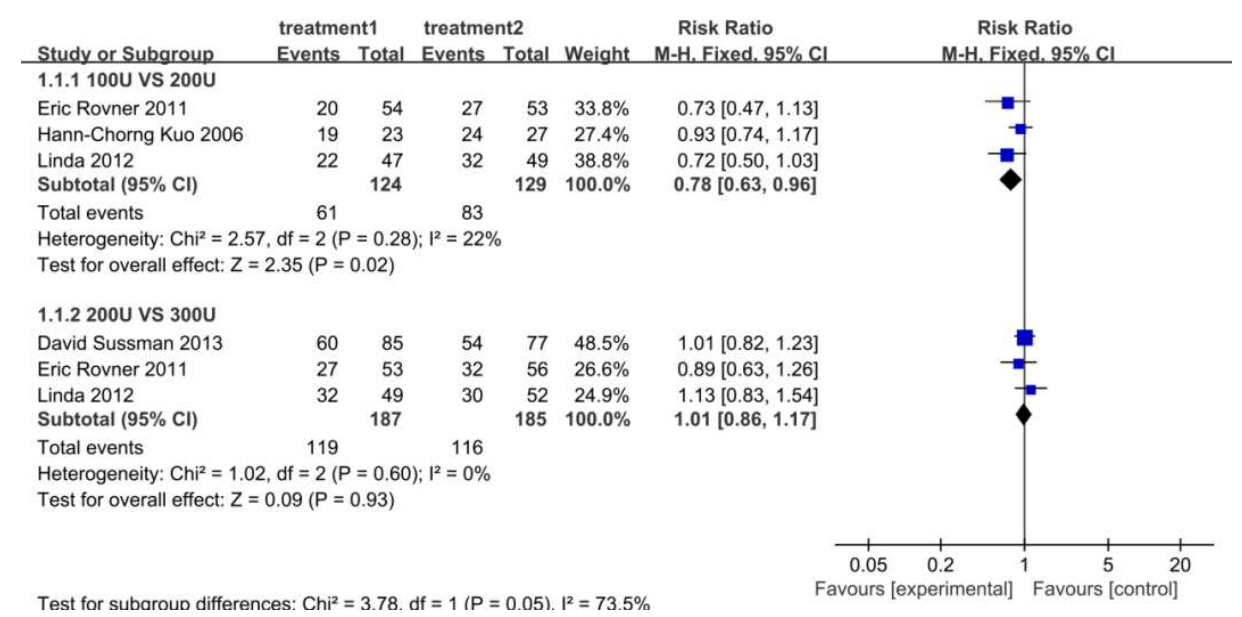

Figure 3. The results of subjective cure rate.

There are four studies $[5,9,15,16]$ analyzing MCC of 100 $\mathrm{U}$ vs. $200 \mathrm{U}$, and showed the significant statistical differences $(P<0.00001$, MD: -63.97, CI 95\%: -82.04 -45.91). Thus, the results indicated that $200 \mathrm{U}$ of onabotulinumtoxinA was superior to $100 \mathrm{U}$ in increasing MCC. Five studies [4, 9-11, 14] analyzed MCC of $200 \mathrm{U}$ VS. $300 \mathrm{U}$, and no statistical differences between them were found. ( $P=0.14$, MD: -15.40 , 95\% CI: -35.63 -4.84) (Figure 4).

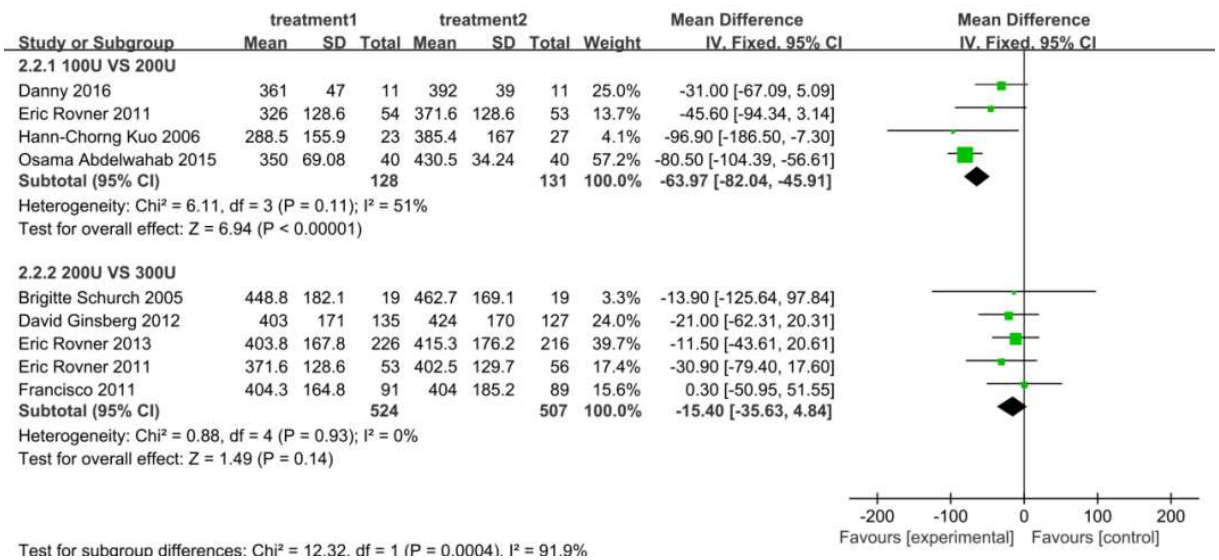

Figure 4. The result of $M C C$.

Likewise, there are four studies $[5,9,15,16]$ about $100 \mathrm{U}$ vs. $200 \mathrm{U}$ and five $[4,9-11,14]$ about $200 \mathrm{U}$ vs. $300 \mathrm{U} .200 \mathrm{U}$ onabotulinumtoxinA showed a robust improvement in the mean change from the baseline than $100 \mathrm{U}$ in decreasing MDP
( $\mathrm{P}<0.00001, \mathrm{MD}: 7.42,95 \%$ CI: 5.15 9.69). The studies about $200 \mathrm{U}$ vs. $300 \mathrm{U}$ showed no statistical differences ( $\mathrm{P}=0.06$, MD: 4.29, 95\% CI: -0.20 8.78) (Figure 5).

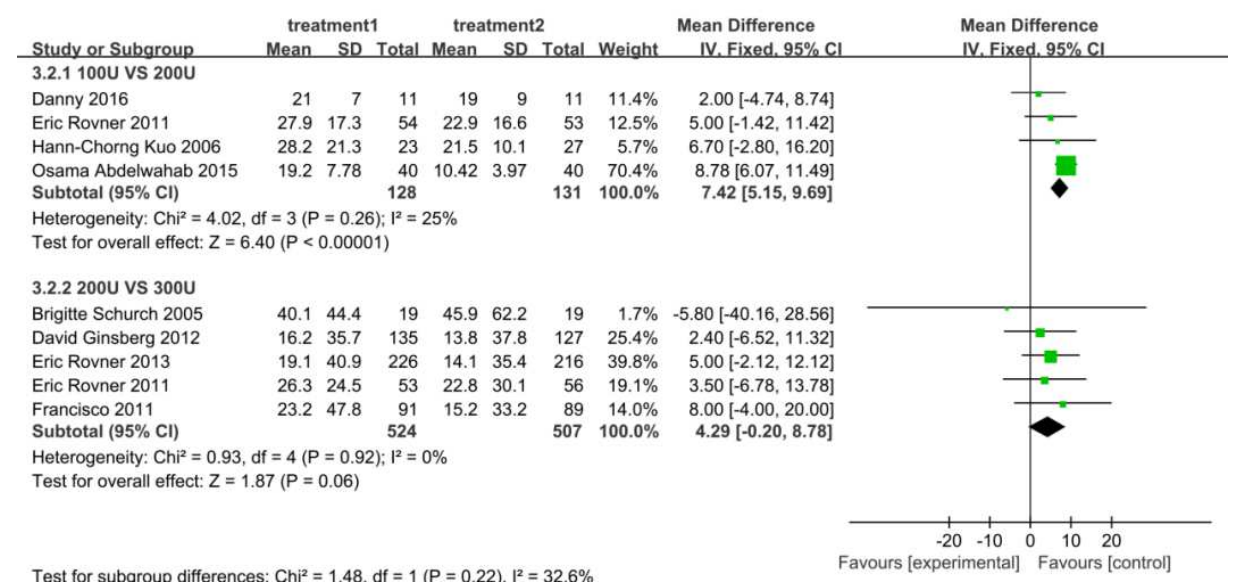

Figure 5. The result of $M D P$ 


\subsection{Urinary Tract Infection}

Five studies $[1,5,13,15,16]$ included the UTI data of $100 \mathrm{U}$ vs. $200 \mathrm{U}$, representing 247 participants $(127$ in the $100 \mathrm{U}$ group, 120 in the $200 \mathrm{U}$ group), and according to our analysis, there were no statistical differences between them $(P=0.23$, RR:
0.80, 95\% CI: 0.56 1.15). Moreover, five [4, 10, 11, 13, 14] studies contained UTI data of $200 \mathrm{U}$ vs. $300 \mathrm{U}$, representing 1029 participants (523 in the $200 \mathrm{U}$ group, 506 in the $300 \mathrm{U}$ group), showing no statistical differences between them, either $(P=0.62$, RR: $0.97,95 \%$ CI: 0.85 1.10) (Figure 6).

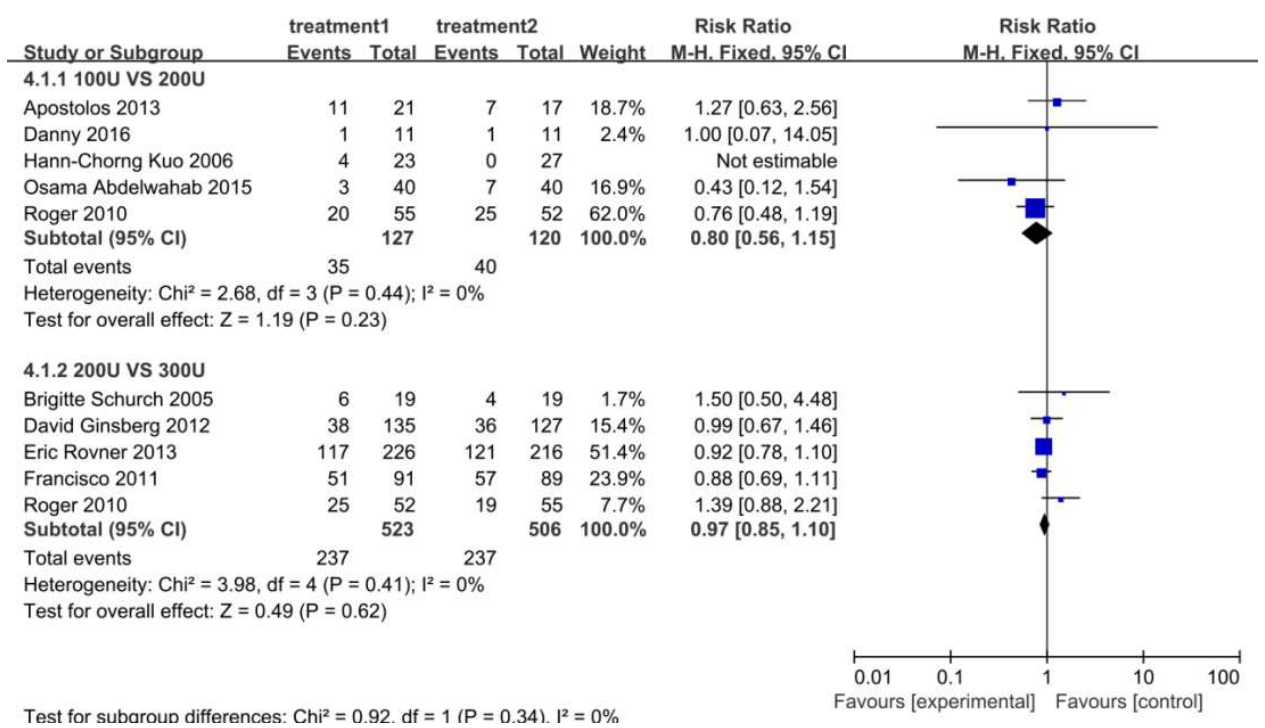

Figure 6. The result of UTI.

\subsection{Urinary Retention}

Four studies $[9,13,15,16]$ included the urinary retention data of $100 \mathrm{U}$ vs. $200 \mathrm{U}$, representing 286 participants (143 in the $100 \mathrm{U}$ group, 143 in the $200 \mathrm{U}$ group), the pooled estimate of $\mathrm{RR}=1.11,95 \% \mathrm{CI}$ was $0.69-1.77(\mathrm{P}=0.67)$, and it showed no statistical differences. Five of the studies [9-11, $13,14]$ included urinary retention data of $200 \mathrm{U}$ vs. $300 \mathrm{U}$, representing 1100 participants (557 in the $200 \mathrm{U}$ group, 543 in the $300 \mathrm{U}$ group), there were no statistical differences between them $(\mathrm{P}=0.25$, RR: $0.88,95 \% \mathrm{CI}: 0.70 \sim 1.10)$ (Figure 7).

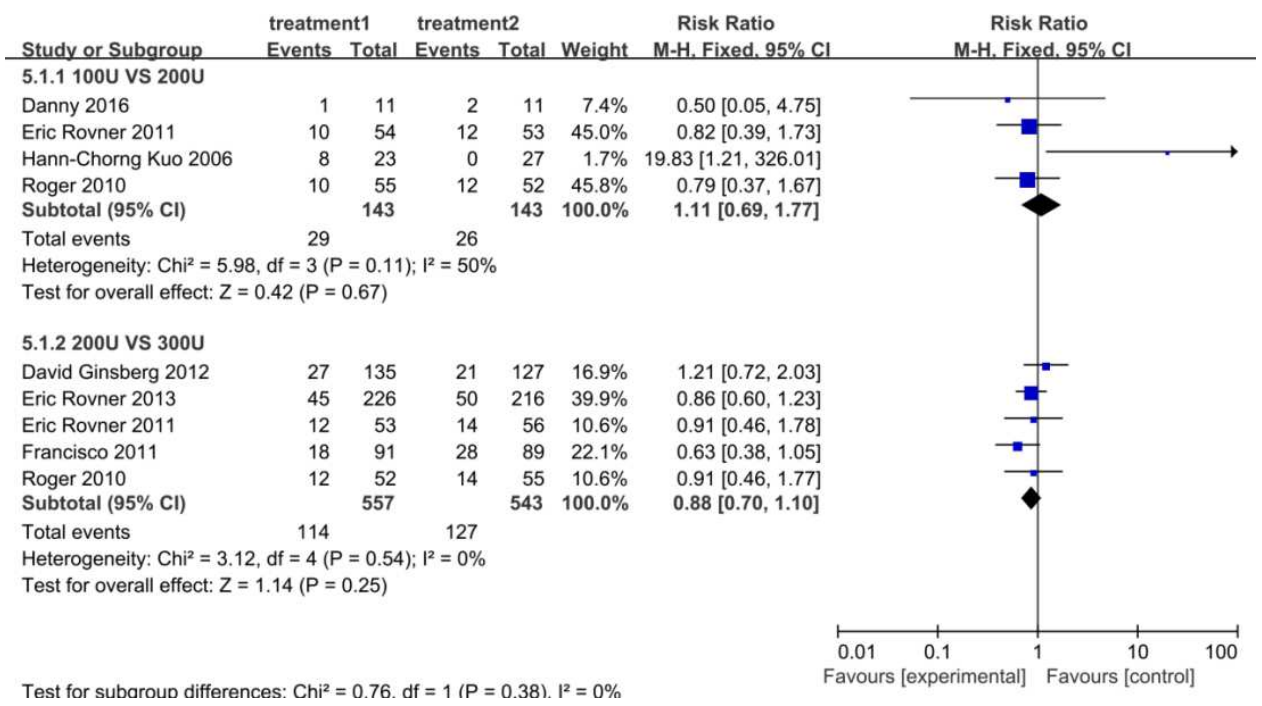

Figure 7. The result of urinary retention.

\section{Discussion}

OnabotulinumtoxinA is currently licensed in certain parts of the world, including China. It is an effective treatment that uses of OnabotulinumtoxinA has already become a second-line treatment in those $\mathrm{OAB}$ patients with failed antimuscarinics and conservative measures, but the optimal dosage has not reached a consensus yet. The majority of published studies have utilized a $300 \mathrm{U}$ dose in adults, but 
some studies reported using dosage from 100 to $400 \mathrm{U}$ OnabotulinumtoxinA [18-21]. YiSun [22] and Yuanshan Cui [23] suggest that OnabotA improves OAB symptoms with manageable side effects. But they did not discuss the dosages of OnabotulinumtoxinA in depth. Tao Cheng [3] only compared $200 \mathrm{U}$ and $300 \mathrm{U}$ of OnabotulinumtoxinA in their study, their result indicated that the use of onabotulinumtoxinA is a well-established treatment method and any significant differences in efficacy between the $300 \mathrm{U}$ dose and the $200 \mathrm{U}$ dose were not observed that consistent with our study. Xin Zhou [24] compared $200 \mathrm{U}$ and $300 \mathrm{U}$ of OnabotulinumtoxinA with limited studies and less participants. Interestingly, we have come to a different conclusion from their study.

The treatment with botulinum toxin is still lacking the standardization, allowing for a great variety in dosing, frequency and injection sites [25].

This analysis suggests a superior dosage of injecting Onabotulinumtoxin A, which acquire a great potential clinical and also economic value. First, from the aspect of efficacy, $200 \mathrm{U}$ of OnabotulinumtoxinA is significantly superior to 100 $\mathrm{U}$ through the longest follow-up time respectively, especially in urodynamic parameters MCC and MDP. The subjective cure rate showed the same tendency but less obvious. Nevertheless, $200 \mathrm{U}$ and $300 \mathrm{U}$ of OnabotulinumtoxinA do not show conspicuous differences. Second, for adverse events, $100 \mathrm{U}$ vs. $200 \mathrm{U}, 200 \mathrm{U}$ vs. $300 \mathrm{U}$ were not found differences according to our study, indicating that these three dosages of OnabotulinumtoxinA might cause adverse events in equal measure. But the price of the treatment is still a matter of debate, in whichever clinical center, the price of $200 \mathrm{U}$ might be equal or even significantly lower comparing to $300 \mathrm{U}$, indicating that the drug could be more affordable and more patients could be treated.

The effect of BoNT/A on inhibiting parasympathetic presynaptic release of acetylcholine (ACh) at the neuromuscular junction is well-known. BoNT/A neurotoxin binds to peripheral cholinergic terminals and inhibits $\mathrm{ACh}$ release at the neuromuscular junction [26]. Therefore, there may be a dose-response relationship according to its mechanism. It may also explain the discrepancy of treatment effects between $100 \mathrm{U}$ and $200 \mathrm{U}$, and why $200 \mathrm{U}$ and $300 \mathrm{U}$ are undifferentiated.

Although the efficacy and safety of this dosage is well-proven, the correct conditions for each particular patient remain still a question, so there are also several potential limitations should be considered in our meta-analysis. Primarily, the causes of overactive bladder syndrome are various, and we do not limit the causes by reason of scanting studies. In addition, because of lacking studies and samples, we can not compare the same parameters within the same follow-up time. However, the study [26] has found that the mean duration of benefit was approximately nine months (36 weeks), thus the longest follow-up times are available to compare. Beyond that, the vast majority of the studies included in our meta-analysis were performed in the Americas and Europe, three of them [7, 9, 11, 27] listed races or ethnicities of participants, and almost all of them were Caucasians or whites. There was one study [16] carried in Taiwan China, but no research has carried out in mainland China yet. The regional discrepancy and the different living habits may also affect treatment outcome.

\section{Conclusion}

In our study, This meta-analysis compares three dosages of OnabotulinumtoxinA for the treatment of $\mathrm{OAB}$, Compared to 100U OnabotulinumtoxinA, 200U OnabotulinumtoxinA has better efficacy while maintaining safety. Although $200 \mathrm{U}$ OnabotulinumtoxinA is comparable to $300 \mathrm{U}$ OnabotulinumtoxinA in terms of safety and efficacy, $200 \mathrm{U}$ OnabotulinumtoxinA is a cost-effective intervention and may appear to be the optimal dosage for OAB populations.

\section{Conflict of Interest Statement}

The authors do not have any possible conflicts of interest.

\section{Acknowledgements}

This work was financially supported by the Natural Science Foundation Program of Shaanxi Province (Grant number: 2020JM-370).

\section{References}

[1] Apostolidis A, Thompson C, Yan X, Mourad S: An exploratory, placebo-controlled, dose-response study of the efficacy and safety of onabotulinumtoxinA in spinal cord injury patients with urinary incontinence due to neurogenic detrusor overactivity. World journal of urology 2013, 31 (6): 1469-1474.

[2] Jundt K, Schreyer K, Friese K, Peschers U: Anticholinergic therapy: do the patients take the pills prescribed? Arch Gynecol Obstet 2011, 284 (3): 663-666.

[3] Cheng T, Shuang WB, Jia DD, Zhang M, Tong XN, Yang WD, Jia XM, Li S: Efficacy and Safety of OnabotulinumtoxinA in Patients with Neurogenic Detrusor Overactivity: A Systematic Review and Meta-Analysis of Randomized Controlled Trials. PLoS One 2016, 11 (7): e0159307.

[4] Schurch B, de Seze M, Denys P, Chartier-Kastler E, Haab F, Everaert K, Plante P, Perrouin-Verbe B, Kumar C, Fraczek S et al: Botulinum toxin type a is a safe and effective treatment for neurogenic urinary incontinence: results of a single treatment, randomized, placebo controlled 6-month study. J Urol 2005, 174 (1): 196-200.

[5] Abdelwahab O, Sherif H, Soliman T, Elbarky I, Eshazly A: Efficacy of botulinum toxin type A 100 Units versus 200 units for treatment of refractory idiopathic overactive bladder. Int Braz J Urol 2015, 41 (6): 1132-1140.

[6] Brubaker L, Gousse A, Sand P, Thompson C, Patel V, Zhou J, Jenkins B, Sievert KD: Treatment satisfaction and goal attainment with onabotulinumtoxinA in patients with incontinence due to idiopathic OAB. Int Urogynecol J 2012, 23 (8): 1017-1025. 
[7] Fowler CJ, Auerbach S, Ginsberg D, Hale D, Radziszewski P, Rechberger T, Patel VD, Zhou J, Thompson C, Kowalski JW: OnabotulinumtoxinA improves health-related quality of life in patients with urinary incontinence due to idiopathic overactive bladder: a 36-week, double-blind, placebo-controlled, randomized, dose-ranging trial. Eur Urol 2012, 62 (1): 148-157.

[8] Sussman D, Patel V, Del Popolo G, Lam W, Globe D, Pommerville P: Treatment satisfaction and improvement in health-related quality of life with onabotulinumtoxinA in patients with urinary incontinence due to neurogenic detrusor overactivity. Neurourol Urodyn 2013, 32 (3): 242-249.

[9] Rovner E, Kennelly M, Schulte-Baukloh H, Zhou J, Haag-Molkenteller C, Dasgupta P: Urodynamic results and clinical outcomes with intradetrusor injections of onabotulinumtoxinA in a randomized, placebo-controlled dose-finding study in idiopathic overactive bladder. Neurourol Urodyn 2011, 30 (4): 556-562.

[10] Rovner E, Dmochowski R, Chapple C, Thompson C, Lam W, Haag-Molkenteller C: OnabotulinumtoxinA improves urodynamic outcomes in patients with neurogenic detrusor overactivity. Neurourol Urodyn 2013, 32 (8): 1109-1115.

[11] Ginsberg D, Gousse A, Keppenne V, Sievert KD, Thompson C, Lam W, Brin MF, Jenkins B, Haag-Molkenteller C: Phase 3 efficacy and tolerability study of onabotulinumtoxinA for urinary incontinence from neurogenic detrusor overactivity. $\mathrm{J}$ Urol 2012, 187 (6): 2131-2139.

[12] Schurch B, Denys P, Kozma CM, Reese PR, Slaton T, Barron RL: Botulinum toxin A improves the quality of life of patients with neurogenic urinary incontinence. Eur Urol 2007, 52 (3): 850-858.

[13] Dmochowski R, Chapple C, Nitti VW, Chancellor M, Everaert K, Thompson C, Daniell G, Zhou J, Haag-Molkenteller C: Efficacy and safety of onabotulinumtoxinA for idiopathic overactive bladder: a double-blind, placebo controlled, randomized, dose ranging trial. J Urol 2010, 184 (6): 2416-2422.

[14] Cruz F, Herschorn S, Aliotta P, Brin M, Thompson C, Lam W, Daniell G, Heesakkers J, Haag-Molkenteller C: Efficacy and safety of onabotulinumtoxinA in patients with urinary incontinence due to neurogenic detrusor overactivity: a randomised, double-blind, placebo-controlled trial. Eur Urol 2011, 60 (4): 742-750.

[15] Altaweel W, Mokhtar A, Rabah DM: Prospective randomized trial of $100 \mathrm{u}$ vs $200 \mathrm{u}$ botox in the treatment of idiopathic overactive bladder. Urol Ann 2011, 3 (2): 66-70.
[16] Kuo HC: Will suburothelial injection of small dose of botulinum A toxin have similar therapeutic effects and less adverse events for refractory detrusor overactivity? Urology 2006, 68 (5): 993-997; discussion 997-998.

[17] Barbagli G, Heidenreich A, Zugor V, Karapanos L, Lazzeri M: Urothelial or oral mucosa cells for tissue-engineered urethroplasty: A critical revision of the clinical outcome. Asian J Urol 2020, 7 (1): 18-23.

[18] Rapp DE, Lucioni A, Bales GT: Botulinum toxin injection: a review of injection principles and protocols. Int Braz J Urol 2007, 33 (2): 132-141.

[19] Bagi P, Biering-Sorensen F: Botulinum toxin A for treatment of neurogenic detrusor overactivity and incontinence in patients with spinal cord lesions. Scandinavian journal of urology and nephrology 2004, 38 (6): 495-498.

[20] Leippold T, Reitz A, Schurch B: Botulinum toxin as a new therapy option for voiding disorders: current state of the art. Eur Urol 2003, 44 (2): 165-174.

[21] Albanese A: Terminology for preparations of botulinum neurotoxins: what a difference a name makes. Jama 2011, 305 (1): 89-90.

[22] Sun Y, Luo D, Tang C, Yang L, Shen H: The safety and efficiency of onabotulinumtoxinA for the treatment of overactive bladder: a systematic review and meta-analysis. International urology and nephrology 2015, 47 (11): 1779-1788.

[23] Cui Y, Zhou X, Zong H, Yan H, Zhang Y: The efficacy and safety of onabotulinumtoxinA in treating idiopathic OAB: A systematic review and meta-analysis. Neurourol Urodyn 2015, 34 (5): 413-419.

[24] Zhou X, Yan HL, Cui YS, Zong HT, Zhang Y: Efficacy and safety of onabotulinumtoxinA in treating neurogenic detrusor overactivity: a systematic review and meta-analysis. Chinese medical journal 2015, 128 (7): 963-968.

[25] Persu C: 300 IU vs. 200 IU of OnabotulinumtoxinA for detrusor overactivity. Central European journal of urology 2014, 67 (1): 41-42.

[26] Seth JH, Dowson C, Khan MS, Panicker JN, Fowler CJ, Dasgupta P, Sahai A: Botulinum toxin-A for the treatment of overactive bladder: UK contributions. Journal of clinical urology 2013, 6 (2): 77-83.

[27] Ginsberg D, Cruz F, Herschorn S, Gousse A, Keppenne V, Aliotta P, Sievert KD, Brin MF, Jenkins B, Thompson C et al: OnabotulinumtoxinA is effective in patients with urinary incontinence due to neurogenic detrusor overactivity regardless of concomitant anticholinergic use or neurologic etiology. Adv Ther 2013, 30 (9): 819-833. 